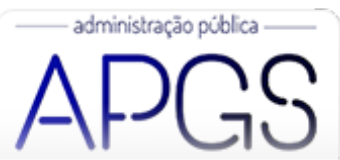

Administração Pública e Gestão Social ISSN: 2175-5787

apgs@ufv.br

Universidade Federal de Viçosa

Brasil

\title{
Práticas de gestão de recursos humanos nas organizações sociais em Portugal: Um estudo exploratório
}

\author{
Jacinta Queirós Bernardino, Susana; de Freitas Santos, José \\ Práticas de gestão de recursos humanos nas organizações sociais em Portugal: Um estudo exploratório \\ Administração Pública e Gestão Social, vol. 12, núm. 1, 2020 \\ Universidade Federal de Viçosa, Brasil \\ Disponible en: http://www.redalyc.org/articulo.oa?id=351561601005
}

Esta obra está bajo una Licencia Creative Commons Atribución-NoComercial-SinDerivar 3.0 Internacional. 


\title{
Práticas de gestão de recursos humanos nas organizações sociais em Portugal: Um estudo exploratório
}

\author{
Human resources management practices in social organizations in Portugal: An exploratory study \\ Prácticas de gestión de recursos humanos en las organizaciones sociales en Portugal: Un estudio exploratorio \\ Susana Jacinta Queirós Bernardino \\ Universidade Portucalense, Portugal \\ Redalyc: http://www.redalyc.org/articulo.oa? \\ id $=351561601005$
}

susanab@iscap.ipp.pt

José de Freitas Santos

Universidade do Minho, Portugal

jfsantos@iscap.ipp.pt

\author{
Recepción: 13 Octubre 2017 \\ Aprobación: 23 Octubre 2018 \\ Publicación: 01 Enero 2020
}

\section{Resumo:}

Os recursos humanos são apontados como um importante ativo para as organizações em geral, sendo particularmente relevantes para as organizações sociais. Este estudo procede à recolha de dados primários, por questionário, junto dos responsáveis das organizações sociais em Portugal, com o objetivo de conhecer as suas práticas de gestão de recursos humanos. Um objetivo complementar do estudo consistiu em compreender se essas práticas variavam (ou não) em função do perfil da organização social e do seu responsável. A investigação quantitativa realizada indicou uma forte valorização das práticas de gestão de recursos humanos, com perfis distintos em função das organizações sociais. Assim, enquanto algumas organizações procuram valorizar a gestão de colaboradores remunerados, outras tendem a concentrar a sua atenção essencialmente na gestão de voluntários. A investigação revela ainda que a valorização de diferentes práticas de gestão de recursos humanos é condicionada pelas características do empreendedor social e do nível de concorrência do ambiente em que as organizações atuam.

Palavras-ChaVe: Organizações sociais, Gestão de recursos humanos, Recrutamento, seleção e integração, Voluntários, Portugal.

\section{Abstract:}

Human resources are described as an important asset for organizations in general and particularly relevant for social organizations. This study collects primary data through a questionnaire sent to representatives of social organizations responsible for social organizations in Portugal. The article aims to understand the practices of human resources management used in those organizations. A complementary objective of the study was to understand whether these practices were different according to the social organization characteristics and the managers' profile. The quantitative research performed revealed a high valuation of human resources management practices, even though different patterns were found according to the social organization features. Thus, while some organizations valued paid employees management, others tend to concentrate their attention primarily on volunteers management. The research also reveals that the valuation of different human resource management practices is conditioned by the social entrepreneur's characteristics and the pressure of the competitive environment in which the organizations act.

KEYWORDS: Social organizations, Human resource management, Recruitment, selection and integration, Volunteers, Portugal.

\section{RESUMEN:}

Los recursos humanos se apuntan como un importante activo para las organizaciones en general, siendo particularmente relevante para las organizaciones sociales. Este estudio procede a la recogida de datos primarios, por cuestionario, entre los responsables de las organizaciones sociales en Portugal, con el objetivo de conocer sus prácticas de gestión de recursos humanos. Un objetivo complementario del estudio consistió en comprender si estas prácticas variaban o no en función del perfil de la organización social y de su responsable.La investigación cuantitativa realizada indicó una fuerte valorización de las prácticas de gestión de recursos humanos, con perfiles distintos en función de las organizaciones sociales. Así, mientras algunas organizaciones buscan valorar la gestión de colaboradores remunerados, otras tienden a concentrar su atención esencialmente en la gestión de voluntarios. La 
investigación revela además que la valorización de diferentes prácticas de gestión de recursos humanos está condicionada por las características del emprendedor social y de la competitividad del ambiente en que las organizaciones actúan.

Palabras Clave: Organizaciones sociales, Gestión de recursos humanos, Reclutamiento, selección e integración, Voluntarios, Portugal.

\section{INTRODUÇÃo}

O empreendedorismo social, enquanto campo de atividade que tende a aplicar um comportamento empreendedor à área social, encontra-se em franca expansão. Nos últimos anos tem-se observado uma forte intensificação do número de organizações sociais, bem como uma ampliação do alcance das suas iniciativas (Bacq \& Janssen, 2011; Mair, 2010; Okpara \& Halkias, 2011). Em Portugal, seguindo a tradição europeia, a economia social e solidária tem sido apontada como o quadro de referência para a prática do empreendedorismo social (Parente, Santos, Marcos, Costa, \& Veloso, 2012). As organizações da economia social são tipicamente organizações de mão-de-obra intensiva, onde os recursos humanos desempenham um papel determinante (Azevedo \& Couto, 2010; Akingbola, 2016) e são apontados com uma importante fonte de vantagem competitiva (Parente, 2010; 2014). Segundo os dados mais recentes da Conta Satélite da Economia Social, publicados em 2016, indica-se que, em 2013, a economia social e solidária em Portugal era responsável por 5,2\% do emprego total e 6,0\% do emprego remunerado (CASES, 2016). Acresce ainda o elevado número de voluntários que o setor mobiliza no país. O Instituto Nacional de Estatística (INE) estima que, em 2012, quase 1 milhão e 40 mil pessoas residentes de 15 anos ou mais tenha se envolvido em atividades de voluntariado (INE, 2016).

Apesar do seu peso na economia, observa-se no dia-a-dia das organizações sociais procedimentos ao nível da gestão de recursos humanos que são desconhecidos da maior parte dos profissionais do setor e uma quase ausência de estudos acadêmicos sobre o tema. Importa, assim, analisar como são geridos os recursos humanos, de modo a compreender de que forma se poderá tornar mais efetiva a gestão de pessoas nas organizações sociais.

Com esta investigação, pretende-se aumentar o conhecimento sobre as práticas de gestão de recursos humanos nas organizações sociais em Portugal, procurando realçar a importância atribuída pelos responsáveis dessas organizações a diferentes questões relacionadas com a gestão das pessoas. Por outro lado, interessa perceber em que medida as práticas de gestão de recursos humanos variam em função do perfil da organização social, de modo a permitir retirar ilações para os diferentes responsáveis dessas organizações.

Tendo em mente o propósito da investigação, o artigo é organizado do seguinte modo: Em primeiro lugar, procede-se a uma revisão da literatura relevante sobre o tema, explorando a importância da gestão de recursos humanos para as organizações sociais e identificando a natureza idiossincrática que a gestão de pessoas nesse tipo de organizações impõe. Segue-se a apresentação das opções metodológicas assumidas para a realização do estudo empírico. Na seção seguinte apresentam-se os principais resultados obtidos, que são depois discutidos. Por fim, são sintetizadas as principais conclusões, apresentando-se ainda pistas para investigação futura.

\section{Sobre AS PRÁticas de GESTÃo DE RECURSOS HUMANOS NA ECONOMIA SOCIAL}

O capital humano é reconhecido como uma importante fonte de vantagem competitiva para as organizações em geral, sendo particularmente relevante para as organizações sociais (Nenobais, Kasim \& Maksum, 2016; Parente, 2010; Parsehyan, 2017). As organizações da economia social são, comumente, organizações de mãode-obra intensiva (Azevedo \& Couto, 2010), onde os colaboradores são o ativo mais importante (Akingbola, 2016). A dimensão empreendedora, porque implica a inovação, a proatividade e a assunção de riscos, torna as pessoas centrais em todos os processos organizacionais. Acresce que o elemento humano traz consigo 
uma variedade de recursos intangíveis, como habilidades, conhecimentos, contatos, referências e reputação (Guclu, Dees \& Anderson, 2002), que são fundamentais para o sucesso das organizações. Por conseguinte, para serem bem-sucedidas, as organizações sociais terão que ter a capacidade para adquirir, desenvolver e manter os seus recursos humanos com as competências necessárias para o desenvolvimento da sua estratégia organizacional (Bloom \& Chatterji, 2009; Bloom \& Smith, 2010). Os resultados empíricos de Sharir e Lerner (2006) confirmam a existência de uma equipe adequada como condição necessária para o sucesso das organizações socialmente empreendedoras. Também em Portugal, a evidência disponível reconhece que os recursos humanos são o recurso mais importante para essas organizações (Nogueira, 2014), apesar de o modelo de gestão de pessoas adotado ser tipicamente de cariz tradicional.

Os empreendedores sociais deparam-se amiúde com desafios peculiares no que diz respeito à mobilização e gestão de recursos humanos (CASE, 2008; Dees, 1998; Domenico, Haugh \& Tracey, 2010; Estrin, Mickiewicz \& Stephan, 2013; Hoogendoorn, Zwan, \& Thurik, 2011; Peredo \& McLean, 2006). O caráter híbrido das organizaçóes socialmente empreendedoras e a multiplicidade de objetivos pelos quais se regem conduz para que estas necessitem de colaboradores com um conjunto mais vasto de qualidades e competências do que o verificado nos setores tradicionais (setor empresarial e sem fins lucrativos) (Estrin et al., 2013; Royce, 2007). Daqui resulta que a força de trabalho seja geralmente mais heterogênea. Os colaboradores podem ser muito distintos entre si no que tange às características, competências, experiências e (ou) tipo de relações contratuais, na medida em que as necessidades de recursos humanos podem ser supridas através de um corpo de colaboradores remunerados ou de voluntários (Bacq, Hartog, Hoogendoorn \& Lepoutre, 2011; Young, Faulk \& Harvey, 2009). Gallagher, Gilmore e Stolz (2012) consideram a existência de dois tipos de voluntários: (i) Os que têm um papel claramente definido e colaboram de uma forma regular com a organização e (ii) os que apenas ocasionalmente se envolvem nas atividades da organização. Para além de colaboradores e voluntários, a organização social necessita de um corpo de dirigentes.

A diversidade de atores no interior da organização pode dar origem à presença de interesses conflitantes (Bloom \& Smith, 2010; London \& Morfopoulos, 2010; Parente, Costa, Santos \& Amador, 2013). Por isso, torna-se relevante o desenvolvimento de uma gestão cuidada dos recursos humanos (Parente, 2010), de modo que as organizações possam munir-se de uma adequada equipe de colaboradores para cumprir a sua missão social e enfrentar os desafios da sociedade. Para que isso aconteça, o Center for the Advancement of Social Entrepreneurship (CASE, 2008) sugere o desenvolvimento das seguintes práticas organizacionais: (i) Recrutamento, seleção e integração; e (ii) retenção e desenvolvimento do capital humano.

$\mathrm{O}$ recrutamento diz respeito à capacidade que as organizações evidenciam de atrair um conjunto de pessoas interessadas em colaborar com elas. Bloom e Smith (2010) defendem que as organizações sociais, para serem bem-sucedidas, terão que recrutar os melhores colaboradores que satisfaçam as necessidades da organização. Porém, segundo Royce (2007), a natureza heterogênea da organização social poderá dificultar a definição de um perfil para as pessoas que se pretende atrair. Para suprirem as suas necessidades em termos de capital humano, as organizações podem recorrer a diversas fontes de recrutamento. Por um lado, o campo de recrutamento pode estar no setor empresarial, no setor sem fins lucrativos, no setor público e até junto da população-alvo que visa servir. Por outro, a organização pode recorrer ao serviço de voluntários ou colaboradores assalariados. Qualquer uma destas fontes de recrutamento proporciona vantagens e inconvenientes, que cada organização deverá ponderar na decisão sobre a alternativa mais adequada e suscetível de produzir os melhores resultados (Dees, 1998).

O recurso ao voluntariado representa uma forma de captação de recursos humanos interessante do ponto de vista econômico. Todavia, diversos autores alertam para os riscos da dependência exclusiva de voluntários (Dees, 1998; Gallagher et al., 2012; Leadbeater, 1997; Royce, 2007). De acordo com o Artigo $3^{\circ}$ da Lei n. ${ }^{\circ} 71 / 98$, de 3 de novembro de 1998, que estabelece as bases de enquadramento jurídico do voluntariado, os voluntários são definidos como indivíduos que "de forma livre, desinteressada e responsável se comprometem, de acordo com as suas aptidões e no seu tempo livre, a realizar ações de voluntariado no 
âmbito de uma organização promotora”. Um colaborador assalariado, pelo contrário, dispõe de um contrato de trabalho, segundo o qual "uma pessoa singular se obriga, mediante retribuição, a prestar a sua atividade a outra ou outras pessoas, no âmbito de organização e sob a autoridade destas" (artigo $11^{\circ}$ da Lei n..$^{\circ}$ /2009, de 12 de fevereiro de 2009).

A natureza não contratual da relação de voluntariado pode culminar numa situação de grande vulnerabilidade para o funcionamento normal da organização. Segundo Gallagher et al. (2012), a perda de voluntários-chave pode conduzir a uma lacuna difícil de colmatar e afetar as probabilidades de sobrevivência da organização.

O recrutamento de colaboradores do setor privado, por sua vez, potencializa a aquisição de pessoas que detêm competências-chave na área empresarial e que fomentam uma cultura mais empreendedora. Para Alter (2000), estes colaboradores tendem a ter maior sensibilidade para as questóes financeiras e para as questões relacionadas com a gestão das organizações, elementos importantes para uma organização social bem-sucedida. Contudo, estes indivíduos podem não estar adequadamente alinhados com a causa social da organização ou não conhecer na sua plenitude a atividade do setor sem fins lucrativos (Alter, 2000). O CASE (2008) adverte, ainda, sobre as dificuldades de adaptação das competências dos indivíduos aos desafios do empreendedorismo social. Ao recrutar-se no setor sem fins lucrativos, pelo contrário, a empresa pode ir buscar colaboradores que se encontrem fortemente comprometidos com uma causa social e que já possuam experiência na resolução de problemas sociais.

O recrutamento no setor privado pode também acarretar um inconveniente no que diz respeito à estrutura de custos da organização. O nível salarial é geralmente inferior ao do setor empresarial pelo que, para que a organização consiga atrair e reter esses colaboradores, pode ter que nivelar o seu pacote remuneratório com o setor privado (Alter, 2000). Segundo Alter (2008), este aumento pode provocar um agravamento da estrutura de custos, conduzir a uma situação de desigualdade salarial interna e constituir uma fonte de tensões e desconforto, causada apenas pelo fato de os colaboradores provirem de setores de atividades diferentes.

Em alternativa, as organizações podem, ainda que parcialmente, recrutar junto da sua população-alvo. Para Royce (2007), esta solução é particularmente interessante para organizações que pretendam estimular o mercado de trabalho para indivíduos que possam ser considerados excluídos, designadamente, pessoas com problemas físicos, grupos de pessoas mais vulneráveis ou pessoas socialmente excluídas e que apresentem dificuldades adicionais para ingressarem no mercado de trabalho. Com este tipo de recrutamento, a organização fomentará a autonomia destes indivíduos, que deixam de ser dependentes de um sistema caritativo e passam a fazer parte do processo de criação de valor. As investigações de Leahy e Villeneuve-Smith (2009) e de Villeneuve-Smith e Chung (2013) indicam que esta situação é muito frequente no Reino Unido, onde a maioria das organizações sociais emprega ativamente pessoas desfavorecidas no mercado de trabalho. Ao colaborarem na organização, essas pessoas também desenvolverão as suas competências e, como tal, aumentarão o seu potencial de empregabilidade. Esta opção é consonante com o conceito de empowerment, defendido pelo empreendedorismo social. Contudo, encontrar dentro deste grupo de pessoas indivíduos com as competências necessárias para o exercício dos postos de trabalho pode ser uma tarefa difícil. Royce (2007) alerta igualmente para a dificuldade em convencer as pessoas a mudarem de vida e a se dedicarem à organização social, pelo menos numa fase inicial.

Após o recrutamento, segue-se a seleção, isto é, a identificação do(s) indivíduo(s) que, entre um conjunto de candidatos disponíveis para colaborar com a organização, qual (quais) aparenta (aparentam) ter as características mais adequadas para o cargo que será exercido. Neste processo, Parente et al. (2013) destacam a necessidade de definir os critérios considerados pertinentes que irão orientar a decisão. A literatura salienta igualmente a análise das competências do candidato, bem como a avaliação do alinhamento entre estas, a missão, os objetivos e os valores da organização, e o público-alvo da iniciativa (Akingbola, 2006, 2016; Parente, 2013; Parente et al., 2013; Yunus, 2011). Na visão de Johnson (2000), a organização deve acautelar e gerir eventuais choques entre culturas que podem emergir de um grupo heterogêneo de colaboradores, 
muitos deles marcados por contextos organizacionais distintos. Harris e Kor (2013) sublinham que uma estratégia bem-sucedida de seleção envolve uma comunicação clara sobre os objetivos da empresa, desafios e recursos disponíveis, bem como oportunidades de crescimento pessoal para os colaboradores. Em Portugal, Nogueira (2014) reconhece a valorização por parte dos gestores de organizações sociais de indivíduos com perfil caracterizado por elevada polivalência, disponibilidade, comprometimento, confiança, proximidade afetiva, voluntarismo e sentido de missão dos colaboradores, sendo conferida primazia a requisitos alusivos ao relacionamento interpessoal em detrimento das qualificações. Terminados os processos de recrutamento e seleção, será útil o desenvolvimento de um processo de integração dos novos colaboradores, de modo a permitir que estes "se familiarizem com as diferentes vertentes da cultura da organização" (Parente, 2010, p. 331).

No empreendedorismo social é particularmente difícil encontrar pessoas que possuam as competências adequadas, uma vez que se trata de um campo híbrido de intervenção na sociedade (CASE, 2008; Brunt, 2016). Por isso, as iniciativas de empreendedorismo social requerem competências específicas e complexas, que podem não estar presentes nos colaboradores no momento em que ingressam na organização (Royce, 2007). O processo de formação e desenvolvimento das pessoas revela-se aqui determinante para que as lacunas detetadas possam ser colmatadas (Johnson, 2000; Royce, 2007) e para que os colaboradores estejam aptos a desempenhar as suas funções da melhor forma possível. Akingbola (2016) sustenta que o ponto de partida das ações de formação em organizações sociais envolve a sensibilização para a missão e para os valores da organização. Harris e Kor (2013), mais recentemente, assinalam que uma grande proporção da formação nas organizações socialmente empreendedoras ocorre de um modo verbal e informal, destacando o papel positivo que o mentoring e coaching assumem no processo de aprendizagem. O CASE (2008) reconhece a dificuldade no desenvolvimento das competências necessárias ao empreendedorismo social, argumentando que, se por um lado são poucas as organizações com uma dimensão suficiente para que possam ser desenvolvidos programas internos, por outro lado, os programas de formação externos têm sido considerados insuficientes face às necessidades existentes. No mesmo sentido, Leahy e Villeneuve-Smith (2009) constatam que a maioria das organizações admite que as competências e formação disponíveis são uma barreira para o exercício do empreendedorismo social.

Para além da constituição de uma equipe com as competências apropriadas, as organizações terão que adotar uma estrutura organizacional para que possam articular as suas atividades de uma forma adequada (Leadbeater, 1997). A estrutura organizacional define, segundo Collis e Montgomery (1981), as relações formais entre os grupos e os indivíduos dentro de uma organização, a alocação de autoridade e o modo como a organização se encontra dividida. As estruturas moldam os canais de comunicação e o processo de tomada de decisão no seio da organização (Teare \& Ingram, 1993). A literatura da especialidade sugere que as estruturas orgânicas e descentralizadas são as mais adequadas para o empreendedorismo social (Austin, Leonard, Reficco \& Wei-Skillern, 2008; Leadbeater, 1997; Patel \& Mehta, 2011; Young et al., 2009). De fato, este tipo de estruturas promove a colaboração interdepartamental e a interação entre os colaboradores da organização, que são importantes para o estímulo de uma cultura de criatividade, abertura e partilha de ideias entre os vários elementos da organização (Leadbeater, 1997; London \& Morfopoulos, 2010). Uma cultura de inovação permanente irá melhorar a capacidade de formulação de respostas a problemas/oportunidades sociais e permitirá uma melhor interação com a envolvente externa da organização (Austin et al., 2008; Young et al., 2009). Este tipo de configuração é consentâneo com a presença de lideranças coletivas e colaborativas, que alguns consideram como particularmente eficazes no empreendedorismo social (Ferreira, 2005; Korosec \& Berman, 2006; Lyons \& Lichtenstein, 2010).

Para que os colaboradores se comprometam com as atividades da organização, é fundamental que se encontrem motivados. Atendendo aos desafios com que as organizações sociais se deparam, a motivação tem sido apontada como um elemento crucial ao sucesso das organizações. Como sugerido por Leadbeater (1997, p. 71), “estas organizações são construídas sobre a energia e entusiasmo das pessoas". Os mecanismos 
de que os empreendedores sociais dispõem para motivar os seus colaboradores são, contudo, diferentes dos existentes no setor empresarial. No empreendedorismo social, os salários são frequentemente menos competitivos (Certo \& Miller, 2008), o que representa uma dificuldade acrescida para a motivação dos colaboradores, em particular para aqueles que têm necessidades significativas de compensação financeira ou que tenham outras oportunidades no mercado de trabalho (Guclu et al., 2002). Baral, Simons, Lane e Zhang (2012) evidenciam empiricamente que a maioria das organizações sociais considera o acesso e retenção de colaboradores como um verdadeiro desafio. Do mesmo modo, Harris e Kor (2013) apontam a rotação de pessoal não planejada, tanto ao nível operacional como de gestão, como uma dificuldade de destaque no empreendedorismo social. Para incrementar o nível de motivação dos colaboradores, as organizações sociais terão que recorrer a outros estímulos de natureza não-financeira. A satisfação intrínseca associada à prossecução de uma missão social, pela qual se encontram sensibilizados, pode ser um desses benefícios não pecuniários (Alter, 2000; Dees, 1998; Guclu et al., 2002; Zhang \& Swanson, 2013; Yunus, 2011). Harris e Kor (2013) verificam que a aplicação de salários competitivos não é uma solução para a redução da rotação de pessoal no empreendedorismo social, defendendo a aplicação conjunta de incentivos monetários e nãomonetários, onde a ligação psicológica dos colaboradores à organização desempenha um papel importante.

A forma como a organização é gerida pode também estimular a motivação dos indivíduos, designadamente através (Alter, 2000; Parente, 2013; Parente et al., 2013; Parsehyan, 2017; Selden \& Sowa, 2015; Young et al., 2009; Zhang \& Swanson, 2013) de:

i. Concepção e atribuição de tarefas desafiadoras, definição de responsabilidades e desenvolvimento profissional dos colaboradores;

ii. Concepção de sistemas de liderança partilhados, de processos de tomada de decisão participativos e da manutenção de uma comunicação aberta;

iii. Implementação de sistemas formais de avaliação e compensação do desempenho, nomeadamente através do reconhecimento e louvor pelo trabalho bem feito;

iv. Criação e manutenção de um bom ambiente de trabalho.

Desta forma, a organização melhora a capacidade de atrair colaboradores profissionais que valorizam essencialmente a dimensão intrínseca do trabalho, que pretendem uma maior autonomia na aplicação do seu conhecimento e que preferem trabalhar com e para as pessoas (Parente et. al., 2013; Schepers et al., 2005; Young et al., 2009).

Parente (2013), analisando a forma como é feita a gestão do capital humano em organizações da economia social em Portugal, assinala que, apesar de a grande maioria das unidades afirmar desenvolver práticas de gestão de pessoas, na realidade a sua orientação é essencialmente de curto prazo. Deste modo, encontra uma presença muito débil da gestão estratégica, pouco orientada para o desenvolvimento pessoal e profissional de todos os recursos humanos. Ferreira (2005), por sua vez, através da realização de entrevistas semiestruturadas, evidencia que a gestão de recursos humanos é uma das atividades centrais do trabalho do "empresário social" em Portugal e que lhe consome uma parte muito significativa do seu tempo de trabalho.

\section{Metodologia}

Com esta investigação, pretende-se aumentar o conhecimento sobre o modo como é feita a gestão dos recursos humanos nas organizações da economia social em Portugal, de modo a perceber quais as práticas que mais são valorizadas pelos gestores dessas organizações.

Para atingir esse propósito, a investigação recorre a uma abordagem quantitativa. Para a recolha dos dados primários foi feito uso de um inquérito por questionário, que foi administrado através de uma plataforma online (Lime Survey). Como unidades de análise consideram-se as organizações não governamentais para o desenvolvimento registadas em Portugal e os projetos cotados na Bolsa de Valores Sociais. 
As organizações não governamentais para o desenvolvimento são entendidas como pessoas coletivas de direito privado, sem fins lucrativos, que visam "a concepção, a execução e o apoio a programas e projetos de cariz social, cultural, ambiental, cívico e econômico, designadamente através de ações nos países em vias de desenvolvimento" (Artigo 6 ${ }^{\circ}$, n. ${ }^{\circ}$ 1, da Lei n. ${ }^{\circ}$ 66/98 de 14 de outubro de 1998, estatuto das organizações não governamentais de cooperação para o desenvolvimento). A Bolsa de Valores Sociais, por sua vez, é uma iniciativa que visa reproduzir, com algumas adaptações, o ambiente de uma bolsa de valores convencional, com o intuito de mobilizar recursos para projetos socialmente empreendedores.

O questionário foi construído pelos investigadores, levando em consideração a revisão de literatura realizada e tomando por base os estudos de Light (2008), National Survey of Third Sector (2008), introduzindo modificações consideradas necessárias aos objetivos da pesquisa.

O questionário era constituído por três seções. A primeira parte visava obter informação relativa à caracterização da organização social e dos respondentes. Na segunda seção procurou-se obter informação relativa à constituição das equipes de trabalho nas organizações da economia social, questionando-se o número de colaboradores e voluntários utilizados pela organização. Por fim, na terceira parte do questionário procurava-se aferir a importância atribuída pelos responsáveis das organizações a diferentes comportamentos relativos à gestão de recursos humanos. Para o efeito foi privilegiado o uso de questões de resposta fechada. Esta opção justifica-se por serem mais objetivas as perguntas, possibilitando a comparação entre casos, e por requererem um menor esforço de resposta por parte dos sujeitos aos quais são aplicadas (Sousa \& Baptista, 2011). Para a medição dos comportamentos dos responsáveis das organizações foram usadas escalas gráficas de 5 pontos, em que 1 corresponde a um fator com pouca importância e 5 , a um fator com muita importância. A escala de medida usada incluiu, assim, um polo positivo (importância muito elevada ou elevada), um polo negativo (importância muito baixa ou baixa) e um polo neutro (importância nula). O instrumento de notação usado foi de encontro à cautela lançada por Hill e Hill (2000), que adverte para o benefício de se incorporar pontos neutros, de modo a não "forçar" o respondente a dar uma resposta direcional (positiva ou negativa) e a enviesar os resultados obtidos.

Após a finalização da versão preliminar do questionário, este foi sujeito a um estudo piloto, através da recolha de opinióes junto a um grupo de especialistas, o que permitiu aumentar a qualidade final do questionário. Antes do envio do questionário, foi estabelecido contato telefônico com as organizações, de modo a confirmar o contato via e-mail para envio do link em que se encontrava alojado o questionário online e para sensibilizar as organizações para a participação no estudo. Foram ainda usados contatos telefônicos e por e-mail para a realização de insistências às não respostas.

Os dados foram recolhidos durante o período compreendido entre 19 de setembro de 2012 e 2 de janeiro de 2013. O processo de recolha de dados permitiu a obtenção de 68 respostas, 62 das quais foram fornecidas por indivíduos envolvidos na gestão da organização e 45 por indivíduos envolvidos na constituição da iniciativa social. A caracterização geral da amostra encontra-se sintetizada na tabela 1 . 
Tabela 1 - Caracterização geral da amostra

\begin{tabular}{|c|c|c|}
\hline Características & $\begin{array}{l}N \\
(68)\end{array}$ & $\%$ \\
\hline \multicolumn{3}{|l|}{ Tipo de organização } \\
\hline BVS & 24 & $35,3 \%$ \\
\hline ONGD & 44 & $89,8 \%$ \\
\hline \multicolumn{3}{|l|}{ Antiguidade da organização } \\
\hline $1-3$ anos & 5 & $7,4 \%$ \\
\hline $3-10$ anos & 32 & $47,1 \%$ \\
\hline$>10$ anos & 31 & $45,6 \%$ \\
\hline \multicolumn{3}{|l|}{ Localização geográfica } \\
\hline Urbana & 59 & $86,76 \%$ \\
\hline Rural & 9 & $13,24 \%$ \\
\hline \multicolumn{3}{|l|}{ Âmbito de atuação } \\
\hline Local & 8 & $11,8 \%$ \\
\hline Regional & 7 & $10,3 \%$ \\
\hline Nacional & 16 & $23,5 \%$ \\
\hline Internacional & 37 & $54,4 \%$ \\
\hline \multicolumn{3}{|l|}{ Finalidade das atividades } \\
\hline A atividade complementa os serviços & & \\
\hline fornecidos por outras organizações & 43 & $63,2 \%$ \\
\hline A atividade concorre com os serviços & & \\
\hline fornecidos por outras organizações & 9 & $13,2 \%$ \\
\hline $\begin{array}{l}\text { A atividade não é disponibilizada por } \\
\text { butras entidades }\end{array}$ & 23 & $33,8 \%$ \\
\hline \multicolumn{3}{|l|}{ Público-Alvo } \\
\hline Pessoas idosas & 16 & $23,5 \%$ \\
\hline \multicolumn{3}{|l|}{ necessidades especiais } \\
\hline Minorias étnicas & 13 & $19,1 \%$ \\
\hline Pessoas com carências financeiras & 22 & $32,4 \%$ \\
\hline Refugiados & 6 & $8,8 \%$ \\
\hline Pessoas com problemas de & 4 & $5,9 \%$ \\
\hline \multicolumn{3}{|l|}{ dependências } \\
\hline Pessoas socialmente & 30 & $44,1 \%$ \\
\hline excluidas/vulneráveis & & \\
\hline Organizações e associaçōes locais & 21 & $30,9 \%$ \\
\hline Outros & 33 & $48,5 \%$ \\
\hline
\end{tabular}

Fonte: Elaboração própria

Para a análise dos dados, dado o caráter exploratório da pesquisa, utilizou-se essencialmente técnicas de estatística descritiva. De modo a permitir uma melhor leitura dos resultados obtidos, procedeu-se ainda à redução de dados, através da análise fatorial por componentes principais. Para o efeito foiutilizada a rotação ortogonal, através do método varimax, com normalização de Kaiser. O tratamento estatístico dos dados foi obtido por recurso ao programa SPSS versão 20. Na seção seguinte procede-se à descrição dos principais resultados obtidos.

\section{ANÁLISE DOS RESULTADOS}

\subsection{Sobre as equipes de trabalho nas organizações de empreendedorismo social}

A análise dos dados revela que as organizações de economia social e solidária em Portugal trabalham em média com equipes constituídas por cerca de 20 colaboradores remunerados e cerca de 150 voluntários. No entanto, como a análise do desvio padrão revela, verifica-se uma grande variabilidade dos resultados obtidos (tabela 2). Uma das organizações refere, inclusive, recorrer a mais de 6.000 voluntários. A análise dos 
quartis revela que as organizações dispõem de equipes de colaboradores remunerados de pequena dimensão. Como se observa na tabela 2, um quarto das organizações (quartil inferior) indica trabalhar com menos do que 2 colaboradores remunerados e metade das organizações trabalha com menos de 7 colaboradores nessa condição laboral (mediana). Relativamente ao número de voluntários envolvidos nas atividades, verificase que estes são utilizados em número superior aos colaboradores remunerados, uma vez que um quarto das organizações sociais (quartil inferior) opera com 6 ou menos voluntários e metade (mediana), com menos de 14 pessoas em regime de voluntariado. Os dados sugerem ainda que a presença de voluntários nas equipes de trabalho é expressiva, observando-se que estes, em média, representam 57,8\% das equipas de trabalho. Verifica-se ainda que apenas 3 organizações (5\%) atuam com uma percentagem nula de voluntários, enquanto $16,1 \%$ recorre exclusivamente a voluntários. A análise do percentil superior indica que um quarto das organizações trabalha com um ratio de voluntários superior a 96,2\%.

Tabela 2 - Caracterização das equipas de trabalho nas organizações sociais

\begin{tabular}{|l|l|l|l|l|}
\hline & $\begin{array}{l}\text { Número de } \\
\text { colaboradores }\end{array}$ & $\begin{array}{l}\text { Número de } \\
\text { voluntários }\end{array}$ & $\begin{array}{l}\text { Dimensão } \\
\text { total das } \\
\text { trabalhas de }\end{array}$ & $\begin{array}{l}\text { Percentagem } \\
\text { de } \\
\text { voluntários }\end{array}$ \\
\hline Média & 20,3 & 149,3 & 170,0 & $57,8 \%$ \\
\hline $\begin{array}{l}\text { Desvio } \\
\text { Padrão }\end{array}$ & 35,1 & 826,0 & 825,6 & $35,4 \%$ \\
\hline $\begin{array}{l}\text { Mínimo } \\
\text { Máximo }\end{array}$ & 0 & 0 & 3 & $0,0 \%$ \\
\hline $\begin{array}{l}\text { Percentil } \\
25\end{array}$ & 2,0 & 6400 & 6412 & $100,0 \%$ \\
\hline $\begin{array}{l}\text { Percentil } \\
50\end{array}$ & 7,0 & 6,0 & 13,5 & $23,6 \%$ \\
\hline $\begin{array}{l}\text { Percentil } \\
75\end{array}$ & 20,3 & 14,0 & 29,5 & $54,3 \%$ \\
\hline
\end{tabular}

Fonte: Elaboração própria

Excluída a organização considerada outlier, que apresentava um número de voluntários superior a 6.000, procedeu-se à análise da constituição das equipes de trabalho em função das características da organização. Conforme se observa na tabela 3 , a análise de dados indica que as organizações mais recentes operam com um baixo número de colaboradores remunerados (média de 4), que tende a aumentar à medida que a organização se encontra estabelecida há mais tempo no mercado (média de 34 em organizações com constituídas há mais de 10 anos). O número médio de voluntários tende também a aumentar com o passar do tempo da organização, mas não de uma forma tão expressiva como o número de colaboradores remunerados. Isso significa que as organizações mais recentes são muito mais dependentes do recurso ao voluntariado (que representa, em média, $76 \%$ da força de trabalho), do que as organizações com um maior nível de senioridade (em que os voluntários são utilizados quase na mesma proporção que os colaboradores remunerados).

Organizações localizadas em centros urbanos contam com equipes ligeiramente superiores às localizadas em centros rurais (média de 65 e 56 indivíduos, respectivamente), mas recorrem de uma forma muito mais expressiva ao voluntariado (61\% e 19\%, respectivamente). É notável que nas organizações fora das principais cidades do país o número de colaboradores remunerados tende a ser superior ao número de voluntários envolvidos na organização. De acordo com a análise da tabela 3, verifica-se ainda que as organizações de âmbito internacional recorrem de uma forma mais pronunciada à prática do voluntariado, com uma percentagem média de voluntários na organização de $68 \%$. 
Susana Jacinta Queirós Bernardino, et al. Práticas de gestão de recursos humanos nas organizaÇões ...

Tabela 3 - Caracterização das equipes de trabalho em função das características da organização (valores médios)

\begin{tabular}{|c|c|c|c|c|}
\hline & $\begin{array}{l}\text { Número de } \\
\text { colaboradores }\end{array}$ & $\begin{array}{l}\text { Número de } \\
\text { voluntários }\end{array}$ & $\begin{array}{l}\text { Dimensão } \\
\text { total das } \\
\text { equipas }\end{array}$ & $\begin{array}{l}\text { Percentagem } \\
\text { de } \\
\text { voluntários }\end{array}$ \\
\hline \multicolumn{5}{|l|}{$\begin{array}{l}\text { Antiguidade } \\
\text { da } \\
\text { organização }\end{array}$} \\
\hline $1-3$ anos & 4 & 35 & 39 & 0,76 \\
\hline $3-10$ anos & 9 & 36 & 45 & 0,65 \\
\hline$>10$ anos & 34 & 52 & 88 & 0,47 \\
\hline \multicolumn{5}{|l|}{$\begin{array}{l}\text { Localização } \\
\text { da } \\
\text { organização }\end{array}$} \\
\hline Urbana & 18 & 47 & 65 & 0,61 \\
\hline Rural & 37 & 9 & 56 & 0,19 \\
\hline \multicolumn{5}{|l|}{$\begin{array}{l}\text { Ámbito de } \\
\text { atuaçâao }\end{array}$} \\
\hline Local & 42 & 21 & 63 & 0,47 \\
\hline Regional & 16 & 6 & 22 & 0,22 \\
\hline Nacional & 36 & 42 & 80 & 0,47 \\
\hline Internacional & 11 & 53 & 63 & 0,68 \\
\hline \multicolumn{5}{|l|}{$\begin{array}{l}\text { Finalidade } \\
\text { das } \\
\text { atividades }\end{array}$} \\
\hline \begin{tabular}{l}
\multicolumn{1}{c}{ A atividade } \\
complementa \\
os serviços \\
fornecidos por \\
outras \\
organizações
\end{tabular} & 17 & 58 & 75 & 0,62 \\
\hline $\begin{array}{l}\text { A atividade } \\
\text { concorre com } \\
\text { os serviços } \\
\text { fornecidos por } \\
\text { outras } \\
\text { organizaçōes }\end{array}$ & 44 & 14 & 58 & 0,37 \\
\hline $\begin{array}{l}\text { A atividade } \\
\text { não é } \\
\text { disponibilizada } \\
\text { por outras } \\
\text { entidades }\end{array}$ & 19 & 31 & 50 & 0,54 \\
\hline
\end{tabular}




\begin{tabular}{|c|c|c|c|c|}
\hline Público-Alvo & & & & \\
\hline Pessoas idosas & 41 & 73 & 114 & 0,63 \\
\hline $\begin{array}{l}\text { Pessoas com deficiência } \\
\text { física elou necessidades } \\
\text { especiais }\end{array}$ & 31 & 45 & 76 & 0,41 \\
\hline Minorias étnicas & 33 & 57 & 92 & 0,61 \\
\hline Pessoas com carências & 20 & 43 & 63 & 0,60 \\
\hline financeiras & & & & \\
\hline Refugiados & 6 & 104 & 110 & 0,82 \\
\hline $\begin{array}{l}\text { Pessoas com problemas } \\
\text { de dependências }\end{array}$ & 9 & 17 & 26 & 0,45 \\
\hline $\begin{array}{l}\text { Pessoas socialmente } \\
\text { excluidas /vulneráveis }\end{array}$ & 17 & 70 & 87 & 0,62 \\
\hline $\begin{array}{l}\text { Organizações e } \\
\text { associaçốes locais }\end{array}$ & 20 & 40 & 60 & 0,59 \\
\hline Outros & 14 & 251 & 265 & 0,65 \\
\hline
\end{tabular}

Fonte: Elaboração própria.

Percebe-se ainda que as organizações cujos produtos ou serviços permitem completar a atividade já fornecida por outras entidades recorrem geralmente a um elevado número de voluntários (média de 58 e rácio de voluntariado de 62\%). Ao invés, as organizações sociais que de alguma forma concorrem com outras entidades apostam numa equipe de colaboradores remunerados (número médio de colaboradores remunerados de 44, com uma percentagem de voluntariado de apenas $37 \%$ ).

\subsection{Sobre A RELEVÂNCIA ATRIBUÍDA ÀS PRÁtiCAS DE GESTÃo DE RECURSOS HUMANOS}

A análise dos dados revela que os responsáveis das organizações sociais atribuem uma forte relevância às práticas de gestão de recursos humanos, conforme se observa na tabela 4. Entre os parâmetros avaliados, aquele que é assumido como mais importante na gestão da organização é a comunicação entre os elementos da organização (média de 4,6), seguindo-se o encorajamento das unidades dentro da organização a trabalharem em conjunto (média de 4,3) ae-exequo com a gestão dos grupos de trabalho dentro da organização (média de 4,3). O recrutamento e a retenção de recursos humanos assumem também uma importância elevada, seja ao nível dos colaboradores remunerados (média de 4,0), voluntários (média de 4,2) ou equipe de gestão e de liderança (média de 4,2). A gestão de colaboradores remunerados é a rubrica que apresenta uma maior heterogeneidade de respostas, como denuncia a análise do desvio padrão, embora a média observada nesta dimensão seja um pouco inferior à observada na gestão de voluntários ou de gestores. De qualquer modo, vale destacar que metade das organizações respondentes atribuiu a importância máxima ( 5 valores na escala) ao recrutamento e retenção de colaboradores.

A variável menos valorizada é a assunção de riscos pelos colaboradores (média de 3,7), o que sugere que apesar de o risco ser apanágio de um comportamento empreendedor, as organizações sociais serão ainda bastante conservadoras quanto ao risco a ser assumido pelos seus colaboradores.

De modo a facilitar a análise de dados e poder fazer uma melhor leitura dos resultados obtidos, procedeuse à redução dos dados (Análise Fatorial por Componentes Principais), que levou à extração de três fatores relativos a elementos da gestão de recursos humanos (tabela 5). O primeiro, que foi designado de gestão dos colaboradores, é composto pelas variáveis "recrutamento e retenção de colaboradores", "envolvimento dos colaboradores na tomada de decisões" e "encorajamento dos colaboradores a assumir riscos". O segundo resulta da aglutinação das variáveis "grupos de trabalho", "encorajar as unidades a trabalhar em conjunto" e "comunicação entre os elementos da organização", que foi apelidado de trabalho em equipe. Por fim, a variável "recrutamento e retenção de voluntários" compõe a terceira dimensão, chamada de gestão de voluntários. 
Após o apuramento das componentes principais, construiu-se os respectivos índices com base na média ponderada dos pesos fatoriais das variáveis nas componentes.

Tabela 4 - Valorização atribuída às variáveis de gestão de recursos humanos

\begin{tabular}{|c|c|c|c|c|c|c|c|c|c|c|}
\hline & (1) & (2) & (3) & (4) & (5) & Média & Desvio-Padrão & $\begin{array}{l}\text { Percentil } \\
25\end{array}$ & $\begin{array}{l}\text { Percentil } \\
50\end{array}$ & $\begin{array}{l}\text { Percentil } \\
75\end{array}$ \\
\hline $\begin{array}{l}\text { Recrutamento } \\
\text { e retenção de } \\
\text { colaboradores }\end{array}$ & $11,3 \%$ & $3,2 \%$ & $6,5 \%$ & $29,0 \%$ & $50,0 \%$ & 4,0 & 1,32 & 4,0 & 4,5 & 5,0 \\
\hline $\begin{array}{l}\text { Recrutamento } \\
\text { e retenção de } \\
\text { voluntários }\end{array}$ & $3,2 \%$ & $1,6 \%$ & $12,9 \%$ & $38,7 \%$ & $43,5 \%$ & 4,2 & 0,95 & 4,0 & 4,0 & 5,0 \\
\hline $\begin{array}{l}\text { Recrutamento } \\
\text { e retenção da } \\
\text { equipe de } \\
\text { gestão e de } \\
\text { liderança }\end{array}$ & $3,2 \%$ & $1,6 \%$ & $8,1 \%$ & $41,9 \%$ & $45,2 \%$ & 4,2 & 0,92 & 4,0 & 4,0 & 5,0 \\
\hline $\begin{array}{l}\text { Os grupos de } \\
\text { trabalho } \\
\text { dentro da } \\
\text { organização. }\end{array}$ & $1,6 \%$ & $3,2 \%$ & $8,1 \%$ & $38,7 \%$ & $48,4 \%$ & 4,3 & 0,88 & 4,0 & 4,0 & 5,0 \\
\hline $\begin{array}{l}\text { o } \\
\text { envolvimento } \\
\text { dos } \\
\text { colaboradores } \\
\text { na tomada de } \\
\text { decisóes. }\end{array}$ & $4,8 \%$ & $3,2 \%$ & $9,7 \%$ & $37,1 \%$ & $45,2 \%$ & 4,2 & 1,05 & 4,0 & 4,0 & 5,0 \\
\hline $\begin{array}{l}\text { Encorajar os } \\
\text { colaboradores } \\
\text { a assumirem } \\
\text { riscos. }\end{array}$ & $8,1 \%$ & $1,6 \%$ & $29,0 \%$ & $35,5 \%$ & $25,8 \%$ & 3,7 & 1,12 & 3,0 & 4,0 & 5,0 \\
\hline $\begin{array}{l}\text { Encorajar as } \\
\text { unidades } \\
\text { dentro da } \\
\text { organização a } \\
\text { trabalharem } \\
\text { em conjunto. }\end{array}$ & $1,6 \%$ & $1,6 \%$ & $19,4 \%$ & $24,2 \%$ & $53,2 \%$ & 4,3 & 0,94 & 4,0 & 5,0 & 5,0 \\
\hline $\begin{array}{l}\text { A } \\
\text { comunicação } \\
\text { entre os } \\
\text { elementos da } \\
\text { organização. }\end{array}$ & $0,0 \%$ & $1,6 \%$ & $8,1 \%$ & $22,6 \%$ & $67,7 \%$ & 4,6 & 0,72 & 4,0 & 5,0 & 5,0 \\
\hline
\end{tabular}

Fonte: Elaboração própria.

$\mathrm{N}=62$; (1) Importância muito baixa; (2) Importância baixa; (3)

Importância nula; (4); Importância elevada; (5) Importância muito elevada;

Como a análise da tabela 5 revela, e tal como a análise das variáveis individuais já havia indiciado, estas três componentes foram classificadas pelos inquiridos como importantes para a organização, como se observa pelas médias obtidas superiores ao ponto 4 da escala. Destaca-se, depois, a importância do trabalho em equipe (média de 4,4), o que denuncia a relevância da existência de um ambiente cooperativo e colaborativo entre os membros da organização, congruente com o caráter coletivo e orgânico das organizações sociais. Igualmente, a valoração da gestão de voluntários (média de 4,2) é ligeiramente superior à gestão de colaboradores (média de 4,0). 
Tabela 5 - Análise de Componentes Principais

\begin{tabular}{|c|c|c|c|c|c|c|}
\hline \multirow{2}{*}{ Componentes } & \multicolumn{6}{|c|}{ Análise de Componentes Principais } \\
\hline & Média & Desvio-padrão & $\begin{array}{l}\text { Valores } \\
\text { Próprios }\end{array}$ & $\begin{array}{l}\% \\
\text { Var. }\end{array}$ & $\begin{array}{l}\text { \% Var. } \\
\text { Acum. }\end{array}$ & $\begin{array}{l}\text { Alpha de } \\
\text { Cronbach }\end{array}$ \\
\hline $\begin{array}{l}\text { Componente 1: Gestão de } \\
\text { colaboradores }\end{array}$ & 4,0 & 1,0 & 3,7 & 46,5 & 46,5 & 0,82 \\
\hline $\begin{array}{l}\text { Componente } 2 \text { : Trabalho } \\
\text { em equipe }\end{array}$ & 4,4 & 0,7 & 1,2 & 15,3 & 61,7 & 0,76 \\
\hline $\begin{array}{l}\text { Componente } 3: \text { Gestão de } \\
\text { voluntários }\end{array}$ & 4,2 & 0,9 & 1,0 & 13,1 & 74,8 & - \\
\hline
\end{tabular}

Fonte: Elaboração própria.

Método de extração: Análise de componentes principais; Método de rotação: varimax, com normalização de Kaiser; Medida de $\mathrm{KMO}=$ 0,796; Teste de esfericidade de Bartlett: $\mathrm{p}=$ 0,000; a. A rotação convergiu em 5 iterações.

Em seguida, procurou-se compreender em que medida a importância conferida a diferentes práticas de recursos humanos diferia, ou não, em função das características da organização e do seu promotor. A análise da tabela 6 revela que as organizações sociais mais recentes (idade inferior a 3 anos) valorizam particularmente o trabalho em equipe (média de 4,75) e a gestão de colaboradores (média de 4,2), em detrimento de uma atuação centrada na gestão de voluntários (média de 3,8). As organizações que foram constituídas há mais tempo (mais de 10 anos), tendem a atribuir uma importância semelhante à gestão de colaboradores (média de 3,9) e de voluntários (média de 4,1). Percebe-se ainda que a relevância atribuída ao trabalho em equipe tende a reduzir ligeiramente à medida que a organização social atinge um maior nível de senioridade.

No que respeita à localização geográfica, verifica-se que as organizações que se localizam em zonas rurais conferem uma maior relevância às práticas de gestão de recursos humanos do que as que encontram-se instaladas em centros urbanos. É possível salientar ainda que as organizações localizadas em centros rurais focam essencialmente a gestão do trabalho em equipe (média de 4,4) e de colaboradores remunerados (média de 4,2), atribuindo uma importância substancialmente menor à gestão de voluntários (média de 3,4). Em organizações localizadas em zonas urbanas, pelo contrário, a importância conferida à gestão de voluntários (média de 4,3) é superior à atribuída à gestão de colaboradores (média de 3,9).

Destaca-se a importância particular que as organizações que lidam com refugiados e pessoas idosas atribuem à gestão de voluntários (4,7 e 4,4 respetivamente). De modo diferente, organizaçóes que intervêm junto a pessoas com problemas de dependências valorizam essencialmente o trabalho em equipe (média de 4,7 ) e a gestão de colaboradores remunerados (média de 4,0), atribuindo uma menor relevância à gestão de voluntários (média de 3,3). 
Tabela 6 - Importância atribuída a diferentes práticas de gestão de recursos humanos em função das características da organização

\begin{tabular}{|c|c|c|c|}
\hline & $\begin{array}{l}\text { Gestão de } \\
\text { colaboradores }\end{array}$ & $\begin{array}{l}\text { Trabalho } \\
\text { em } \\
\text { equipa }\end{array}$ & $\begin{array}{l}\text { Gestão de } \\
\text { voluntários }\end{array}$ \\
\hline \multicolumn{4}{|l|}{$\begin{array}{l}\text { Antiguidade da } \\
\text { organização social }\end{array}$} \\
\hline $1-3$ anos & 4,2 & 4,7 & 3,8 \\
\hline $3-10$ anos & 4 & 4,4 & 4,3 \\
\hline$>10$ anos & 3,9 & 4,3 & 4,1 \\
\hline \multicolumn{4}{|l|}{$\begin{array}{l}\text { Localização } \\
\text { geográfica }\end{array}$} \\
\hline Urbana & 3,9 & 4,4 & 4,3 \\
\hline Rural & 4,2 & 4,4 & 3,4 \\
\hline \multicolumn{4}{|l|}{ Âmbito de atuação } \\
\hline Local & 4,1 & 4,4 & 4,4 \\
\hline Regional & 4,2 & 4,4 & 3,2 \\
\hline Nacional & 4,1 & 4,4 & 4,1 \\
\hline Internacional & 3,8 & 4,4 & 4,3 \\
\hline \multicolumn{4}{|l|}{$\begin{array}{l}\text { Finalidade da } \\
\text { atividade }\end{array}$} \\
\hline $\begin{array}{l}\text { Completar os } \\
\text { serviços por outras } \\
\text { organizaçôes }\end{array}$ & 4 & 4,4 & 4,1 \\
\hline $\begin{array}{c}\text { Concorrer com } \\
\text { outras organizações }\end{array}$ & 4,1 & 4,4 & 4,3 \\
\hline \begin{tabular}{l}
\multicolumn{1}{c}{ Disponibilizar } \\
produtos em áreas \\
não fornecidas por \\
outras entidades
\end{tabular} & 3,7 & 4,4 & 4 \\
\hline
\end{tabular}

\begin{tabular}{|l|l|l|l|}
\hline Público-Alvo & 3,6 & 4,3 & 4,4 \\
$\quad$ Pessoas idosas & 4,0 & 4,6 & 4,1 \\
Pessoas com deficiência física & 4,0 & & \\
ejou necessidades especiais & 4,2 & 4,5 & 4,3 \\
$\quad$ Minorias étnicas & 3,9 & 4,5 & 4,3 \\
$\quad$ Pessoas com carências & 4,1 & 4,8 & 4,7 \\
financeiras & 4,0 & 4,7 & 3,3 \\
$\quad \begin{array}{l}\text { Refugiados } \\
\text { Pessoas com problemas de }\end{array}$ & 4,9 & 4,4 & 4,3 \\
dependências & Pessoas socialmente & 4,4 & 4,2 \\
excluidasivulneráveis & & & \\
Organizaçôes e associações & 4,0 & 4,3 & 4,2 \\
\hline locais & 3,9 & & \\
\hline Outros & & & \\
\hline
\end{tabular}

Fonte: Elaboração própria.

Analisando o âmbito de atuação geográfica, verifica-se que as organizações que operam no nível internacional atribuem uma maior importância à gestão de voluntários do que à gestão de colaboradores remunerados, contrariamente àquilo que se tende a verificar nas outras organizações sociais.

Quando se analisa a finalidade da atividade prosseguida pela organização, constata-se que as organizações que concorrem com outras organizações ou com o Estado na disponibilização de produtos ou serviços conferem uma importância maior à gestão de colaboradores (média de 4,1) do que as organizações que complementam os serviços oferecidos por outras organizações (média de 4,0) ou que operam em áreas em 
que não existe qualquer tipo de oferta (média de 3,75). Não obstante, são também estas as organizações que mais valorizam a gestão de voluntários, com uma média de 4,3, que compara com a média de 4,1 observada em organizações que operam em áreas em que não existe qualquer tipo de fornecimento.

Relacionando agora a importância atribuída às diferentes práticas de gestão de recursos humanos com as características das equipes de trabalho, identifica-se uma associação forte, estatisticamente significativa, entre o recurso ao voluntariado e a importância relativa que é atribuída à "gestão de colaboradores" versus "gestão de voluntários" (tabela 7). Assim, de uma forma não surpreendente, as organizações que fazem um uso mais intensivo de voluntários nas suas equipes são aquelas que mais valorizam a gestão de voluntários $(\mathrm{r}=0,338$, $\alpha=, 01$ ), bem como atribuem um menor grau de relevo à gestão de colaboradores (observável através de um coeficiente de correlação negativo estatisticamente significativo: $r=-0,312, \alpha=0,05)$. Não se identificam correlações estatisticamente significativas entre a importância conferida às diferentes práticas de gestão de recursos humanos e a dimensão das equipes de trabalho, quer ao nível de colaboradores remunerados, quer de voluntários.

Tabela 7 - Análise da correlação entre práticas de gestão de recursos humanos e características das equipes de trabalho

\begin{tabular}{|l|l|l|l|}
\hline & $\begin{array}{l}\text { Gestão de } \\
\text { colaboradores }\end{array}$ & $\begin{array}{l}\text { Trabalho } \\
\text { em equipe }\end{array}$ & $\begin{array}{l}\text { Gestão de } \\
\text { voluntários }\end{array}$ \\
\hline $\begin{array}{l}\text { Número de } \\
\text { colaboradores }\end{array}$ & 0,088 & $-0,029$ & $-0,03$ \\
\hline $\begin{array}{l}\text { Número de } \\
\text { voluntários }\end{array}$ & 0,097 & 0,052 & 0,13 \\
\hline $\begin{array}{l}\text { Dimensão total } \\
\text { das equipes }\end{array}$ & 0,101 & 0,051 & 0,129 \\
\hline $\begin{array}{l}\text { Percentagem de } \\
\text { voluntários }\end{array}$ &,$- 312^{*}$ & $-0,086$ &, $338^{* *}$ \\
\hline
\end{tabular}

Fonte: Elaboração própria.

** A correlação é significativa no nível 0,$01 ;{ }^{*}$ A correlação é significativa no nível 0,05

Centrando a análise nas características demográficas dos mentores da organização social, verifica-se que mulheres valorizam mais a gestão de colaboradores remunerados (média de 4,2) do que os homens (média de 3,6). Em relação às componentes do trabalho em equipe e gestão de voluntários, verifica-se que a valorização dos comportamentos é semelhante entre gêneros, tal como se observa na tabela 8 .

Olhando para a idade do promotor da organização verifica-se igualmente uma maior disparidade em termos da valorização atribuída à gestão de colaboradores remunerados, sendo que aqueles que mais valorizam esta prática organizacional são os respondentes mais jovens (média de 4,4 em indivíduos com idade compreendida entre os 18 e os 34 anos); os respondentes que menos valorizam essaa prática são os que apresentam uma idade superior a 65 anos (média de 3,26). Estes últimos, por sua vez, são também aqueles que mais valorizam a gestão de voluntários (verificando-se uma média de 4,67 numa escala de 1 a 5 valores). A componente trabalho em equipe acolhe uma valoração bastante positiva por parte de todos os respondentes, independente da idade que estes apresentam. 
Tabela 8 - Importância atribuída a diferentes práticas de gestão de recursos humanos em função das características do promotor da organização

\begin{tabular}{|c|c|c|c|}
\hline & $\begin{array}{l}\text { Gestão de } \\
\text { colaboradores }\end{array}$ & $\begin{array}{l}\text { Trabalho } \\
\text { em } \\
\text { equipe }\end{array}$ & $\begin{array}{l}\text { Gestão de } \\
\text { voluntários }\end{array}$ \\
\hline \multicolumn{4}{|l|}{$\begin{array}{l}\text { Posição do } \\
\text { promotor na } \\
\text { iniciativa }\end{array}$} \\
\hline Colaborador & 4,2 & 4,4 & 4,1 \\
\hline Voluntário & 3,7 & 4,3 & 4,4 \\
\hline \multicolumn{4}{|l|}{$\begin{array}{l}\text { Nível de } \\
\text { escolaridade }\end{array}$} \\
\hline $\begin{array}{c}\text { Ensino } \\
\text { Secundário }\end{array}$ & 3,0 & 4,2 & 4,0 \\
\hline $\begin{array}{l}\text { Ensino } \\
\text { Superior }\end{array}$ & 4,0 & 4,4 & 4,2 \\
\hline \multicolumn{4}{|l|}{$\begin{array}{l}\text { Área de } \\
\text { formação }\end{array}$} \\
\hline $\begin{array}{l}\text { Ciências da } \\
\text { saúde }\end{array}$ & 3,7 & 4,6 & 4,5 \\
\hline $\begin{array}{l}\text { Ciências } \\
\text { Sociais }\end{array}$ & 4,8 & 4,4 & 4,3 \\
\hline $\begin{array}{c}\text { Ciências } \\
\text { Económicas }\end{array}$ & 3,7 & 4,4 & 4,4 \\
\hline Engenharia & 4,0 & 4,1 & 4,1 \\
\hline Artes & 4,2 & 4,5 & 4,0 \\
\hline Humanidades & 3,9 & 4,3 & 3,8 \\
\hline Ensino & 4,5 & 4,7 & 4,8 \\
\hline \multicolumn{4}{|l|}{$\begin{array}{l}\text { Situação } \\
\text { profissional } \\
\text { anterior }\end{array}$} \\
\hline Empregado & 3,9 & 4,3 & 4,1 \\
\hline Reformado & 4,2 & 4,9 & 4,5 \\
\hline Não ativo & 4,0 & 4,6 & 4,5 \\
\hline \multicolumn{4}{|l|}{$\begin{array}{l}\text { Setor de } \\
\text { proveniência }\end{array}$} \\
\hline \begin{tabular}{|l} 
Setor \\
Empresarial
\end{tabular} & 3,9 & 4,2 & 4,0 \\
\hline Setor Público & 3,8 & 4,3 & 4,1 \\
\hline $\begin{array}{l}\text { Setor sem fins } \\
\text { lucrativos }\end{array}$ & 4,5 & 4,7 & 4,2 \\
\hline \multicolumn{4}{|l|}{$\begin{array}{l}\text { Situação } \\
\text { ocupacional do } \\
\text { promotor }\end{array}$} \\
\hline Colaborador & 4.2 & 4.4 & 4.1 \\
\hline Voluntário & 3.7 & 4.3 & 4.4 \\
\hline
\end{tabular}

Fonte: Elaboração própria.

De uma forma não surpreendente, verifica-se ainda que os empreendedores sociais que atuam na organização social como colaboradores remunerados valorizam mais a gestão de colaboradores (média de 4,15) do que aqueles que atuam como voluntários (média de 3,67). Verifica-se o inverso em relação à importância conferida à gestão de voluntários, que é mais valorizada pelos empreendedores sociais que colaboram na qualidade de voluntários (média de 4,36, que compara com a média de 4,05 dos empreendedores sociais remunerados).

Não obstante a vasta maioria dos respondentes dispor de formação superior, verifica-se que estes atribuem uma maior relevância a todas as práticas de gestão de recursos humanos do que aqueles que possuem formação 
de nível secundário. A diferença mais expressiva é encontrada ao nível da valoração da gestão de colaboradores (com uma diferença média de cerca de 1 ponto, numa escala de 1 a 5). Os indivíduos que mais valorizam a gestão de colaboradores são os que realizaram a sua formação na área das ciências sociais (média de 4,8), ensino (média de 4,5) ou artes (média de 4,2). Os respondentes que mais valorizam a gestão de voluntários são igualmente os que desenvolveram a sua formação na área do ensino (média de 4,8), bem como ciências da saúde (média de 4,5), ciências econômicas (média de 4,4) e ciências sociais (média de 4,3). Conforme se observa pela análise da tabela 8 , o trabalho em equipe e a gestão de voluntários é mais valorizada por indivíduos que, quando da criação da organização social, se encontravam reformados ou não ativos, do que aqueles que, nesse momento, se encontravam empregados. Nota-se que a maioria dos gestores, quando ingressaram na organização social se encontravam empregados (35), sendo pouco frequentes os casos em que estes encontravam-se reformados (apenas 2).

Indivíduos oriundos do setor social valorizam mais todas as componentes de gestão de recursos humanos em análise (comparativamente com indivíduos provenientes do setor empresarial ou público), sendo a diferença mais expressiva encontrada ao nível da valorização da prática de gestão de colaboradores remunerados.

\section{Discuss Ão dos Resultados}

A investigação realizada indica uma forte valorização das práticas de gestão de recursos humanos por parte dos responsáveis das organizações sociais em Portugal. Os resultados encontrados são compatíveis com outras investigações realizadas no panorama nacional (Ferreira, 2005; Parente, 2013) e com a posição veiculada na literatura sobre a importância das pessoas nas organizações sociais (Azevedo \& Couto, 2010; Akingbola, 2006).

Apesar da relevância conferida aos recursos humanos, identificam-se algumas debilidades na sua gestão, tal como identificado por outros estudos (Parente, 2013).

A análise dos dados indica que as organizações sociais em Portugal caracterizam-se essencialmente por equipes de pequena dimensão, com forte recurso ao voluntariado, embora alguma heterogeneidade seja encontrada entre as diferentes organizações em análise. A expressividade do voluntariado nas iniciativas de empreendedorismo social poderá dever-se ao cenário de escassez de recursos pelo qual estas organizações se tendem a caracterizar, e pela favorabilidade que o voluntariado representa do ponto de vista dos custos de exploração da organização, bem como na facilidade em aceder a determinado perfil de competências de uma forma economicamente atrativa. De fato, o recurso ao voluntariado é particularmente pronunciado em organizações mais recentes, o que poderá justificar-se pela especial limitação de recursos com que as organizações em início de atividade se deparam. Organizações mais recentes, apesar de verem as suas equipes de trabalho constituídas maioritariamente por voluntários, conferem uma maior importância à gestão de colaboradores remunerados do que a indivíduos envolvidos em regime de voluntariado. Assim, essas organizações, embora cientes da importância capital da posse de uma equipe de trabalho estável, suprem grande parte das suas necessidades de pessoal através do voluntariado em virtude da situação financeira com que poderão deparar-se.

O forte peso do voluntariado nas equipas de trabalho vai de encontro ao alerta lançado por Gallagher et al. (2012) sobre o risco que esta situação poderá representar para a prossecução da missão e estratégia da organização social, cuja continuidade ficará dependente da boa vontade e disponibilidade de elementos que não possuem um vínculo contratual com a organização.

O risco de construção de uma estratégia (ainda que na área social) por uma equipe fortemente dependente do voluntariado torna-se ainda mais evidente quando se analisa as atividades desenvolvidas pela organização. Os resultados indicam que as organizações que concorrem com outras entidades tendem a dispor de equipes de trabalho maioritariamente constituídas por colaboradores remunerados, que, presume-se, têm 
um vínculo mais estável com a organização. Assim, organizações sociais que se deparam com um maior nível de concorrência sentem-se obrigadas a gerir o seu capital humano de uma forma mais estratégica, sejam estes colaboradores remunerados ou voluntários. Esta constatação vai de encontro à posição defendida na literatura de que os recursos humanos são uma importante fonte de vantagem competitiva, também para as organizações sociais (Parente, 2010).

A investigação indica que os responsáveis das organizações sociais conferem uma forte relevância à gestão participativa dos colaboradores, evidente na valorização atribuída a questóes como a comunicação e o trabalho em equipe. Esta constatação sugere a tendência para a adoção de estruturas de natureza organicista nas iniciativas de empreendedorismo social, assentada numa forte envolvência e participação dos coladores, tal como sugerido por diversos autores (e.g. Leadbeater, 1997; London \& Morfopoulos, 2010; Austin et al., 2008; Young et al., 2009; Lyons \& Lichtenstein, 2010). O caráter híbrido do empreendedorismo social requer, amiúde, a disposição de colaboradores com um perfil de competências muito vasto, com frequência difícil de encontrar num único colaborador (Estrin et al., 2013; Royce, 2007; CASE, 2008), sendo apenas possível de alcançar através do trabalho conjunto de indivíduos dotados de diferentes capacidades e experiências. O trabalho colaborativo é, aliás, enfatizado pelas organizações mais recentes, o que sugere a importância da colaboração conjunta dos diferentes elementos da organização para se fazer face aos desafios particulares com que estas organizações em início de atividade se deparam, e para as quais os processos de tomada de decisão e de resolução de problemas serão menos estruturados.

A investigação realizada não identificou diferenças significativas ao nível das práticas de gestão de recursos humanos adotadas por organizações com equipes de dimensões diferentes. A priori, poder-se-ia esperar que organizações de menor dimensão conferissem uma maior relevância ao trabalho em equipe do que organizações de maior porte. Esta situação não é, no entanto, evidenciada no estudo empírico, o que corrobora com o caráter colaborativo que se encontra no modus operandi destas organizações, independentemente da sua dimensão.

A análise das práticas de gestão de recursos humanos adotadas pelas organizações sociais sugere a existência de diferentes perfis de organizações no que respeita a sua orientação empreendedora para a gestão do capital humano. De fato, identificam-se organizações que, a par de um forte recurso ao regime de voluntariado, conferem uma importância particular à gestão deste tipo de ativo. Outras organizações, de um modo distinto, tendem a enfatizar a gestão de colaboradores assalariados que, embora mais onerosos, apresentam um vínculo mais estável com a organização. O perfil encontrado é em muito condicionado pela relação contratual do empreendedor social, que tende a imprimir na organização a visão que tem para a gestão de pessoas. Assim, empreendedores sociais que atuam numa lógica de voluntariado valorizam mais a gestão deste grupo de recursos humanos comparativamente com a gestão de trabalhadores assalariados, enquanto se verifica o inverso em empreendedores sociais que se envolveram na organização social na qualidade de colaboradores remunerados. Os resultados obtidos vão de encontro ao alerta lançado por outros investigadores quanto à necessidade de uma maior profissionalização na gestão das organizações sociais (Nogueira, 2014; Parente, 2014).

Para além disso, a investigação indica ainda que as características demográficas do promotor da organização social influem na definição das práticas de gestão de recursos, sendo que organizações fundadas por mulheres e por pessoas mais jovens tendem a valorizar de uma forma mais expressiva a gestão de colaboradores remunerados. Merece destaque a intervenção em organizações sociais, que pode ser desencadeada por diferentes motivações, não só relacionadas com a determinação social, como também com objetivos de caráter pessoal (Bernardino \& Freitas Santos, 2015), onde se inclui a dimensão aprendizagem e desenvolvimento do indivíduo relacionados com o conteúdo e a natureza do trabalho desenvolvido na organização (Amorim, 2015; Bechara \& Bernardino, 2018). Indivíduos provenientes do setor social, provavelmente mais sensibilizados para a importância das pessoas nas organizações sociais, atribuem uma importância superior a todas as práticas de gestão de recursos em análise do que os restantes respondentes. 


\section{Conclusões}

A economia social apresenta uma importância significativa no panorama nacional português, sendo apontado como o campo de referência para a resolução de um vasto conjunto de problemas sociais. A capacidade destas organizações reside, em muito, nas pessoas que as constituem. Com esta investigação, procurou-se traçar um retrato das práticas de gestão de recursos humanos adotados pelas organizações sociais, assim como compreender em que medida essas práticas são similares entre diferentes organizações.

A investigação realizada indicou que o voluntariado assume um peso importante na formação da força de trabalho das organizações sociais, particularmente expressivo em alguns tipos de organizações, tais como organizações em início de atividade.

O estudo realizado sugere que os responsáveis das organizações sociais atribuem uma importância elevada a diferentes práticas de gestão dos seus colaboradores, sejam estes remunerados ou voluntários. Identificamse, todavia, diferentes perfis de organizações, umas que adotam uma abordagem muito centrada na gestão de voluntários e outras que procuram gerir a organização com base numa equipe de trabalho mais estável, procurando conciliar a gestão de colaboradores remunerados com o recurso, subsidiário, ao regime de voluntariado. Verifica-se ainda que a valorização de diferentes práticas de gestão de recursos humanos, em particular nas componentes gestão de colaboradores e gestão de voluntários, é moldada por fatores pessoais do empreendedor social, tais como gênero, idade e vínculo com a organização, bem como pelo nível de concorrência com que a organização social se depara.

Em todos os casos verifica-se uma elevada importância conferida à gestão do trabalho em equipe, o que indica que o empreendedorismo social é um fenômeno eminentemente colaborativo, em que a cooperação entre as diferentes equipes é fundamental para se fazer face aos constantes desafios que a atividade social impõe.

Como principais limitações da investigação apontam-se o número de respostas obtidas, bem como o fato de o estudo empírico se basear no julgamento dos responsáveis das organizações sociais quanto às práticas adotadas no âmbito da gestão dos recursos humanos. Acresce ainda que o estudo foi realizado no contexto português, num período em que o país se defrontava com uma crise econômica e financeira muito severa.

A investigação realizada apresenta uma natureza exploratória, proporcionando importantes contribuições para a gestão de pessoas no âmbito das organizações sociais e procurando avançar o conhecimento numa área que carece ainda de investigação futura. Como linha de investigação futura sugere-se a avaliação do modo como as práticas de recursos humanos adotadas pelas organizações são efetivamente capazes de contribuir para a produção de um maior nível de impacto social e para o incremento do nível de sustentabilidade da organização. Sugere-se ainda a realização de um estudo detalhado acerca das organizações sociais, sobre as principais razões que as levam à contratação de colaboradores remunerados e voluntários, bem como compreender as principais fontes de recrutamento utilizadas. Uma outra área a explorar seria a avaliação dos mecanismos que as organizações dispõem para articular a gestão de pessoas com diferentes vínculos contratuais e para acautelar eventuais conflitos entre colaboradores remunerados e voluntários. Percebese ainda a pertinência da elaboração de um estudo longitudinal, que permita comparar os resultados em diferentes momentos do tempo, bem como a realização de um estudo comparativo entre diferentes países.

\section{REFERÊNCIAS BIBLIOGRÁfICAS}

Akingbola, K. (2006). Strategy and HRM in nonprofit organizations: Evidence from Canada. The International Journal of Human Resource Management, 17 (10), 1707-1725.

Akingbola, K. (2016). Managing Human Resources for Nonprofits. London, Routledge- Taylor Francis Group.

Alter, S. (2000). Managing the double bottom line - A business planning reference guide for social enterprises. Washington, DC: PACT Publications. 
Alter, S. (2008). Social enterprise models and their mission and money relationships. In A. Nicholls (Ed.), Social entrepreneurship: new models of sustainable social change (205-232). New York: Oxford University Press.

Amorim, L. (2015). A motivação para o trabalho dos voluntários da Cruz Vermelha Portuguesa. Dissertação de Mestrado em Gestão das Organizações, Instituto Politécnico de Viana do Castelo, Portugal.

Austin, J., Leonard, H., Reficco, E., Wei-Skillern, J. (2008). Social entrepreneurship: It is for corporations, too. In A. Nicholls (Ed.), Social entrepreneurship: new models of sustainable social change (169 - 180). New York: Oxford University Press.

Azevedo, C.; Couto, P. (2010). O desafio da sustentabilidade das OSFL e as finanças locais. In C. Azevedo, R. Franco, J. Meneses (Eds.), Gestão de organizações sem fins lucrativos (371-407). Lisboa: Vida Económica.

Bacq, S. Janssen, F. (2011). The multiple faces of social entrepreneurship: A review of definitional issues based on geographical and thematic criteria. Entrepreneurship \& Regional Development: An International Journal, 23 (5-6), 373-403.

Bacq, S., Hartog, C., Hoogendoorn, B., \& Lepoutre, J. (2011). Social and commercial entrepreneurship: Exploring individual and organizational characteristics. Scales Research Reports, EIM Business and Policy Research. Acedido em janeiro 29, 2017, em http://www.ondernemerschap.nl/sys/cftags/assetnow/design/widgets/site/ ctm_getFile.cfm?file=H201110.pdf\&perId=615

Baral, S., Simons, K., Lane, A., Zhang, C. (2012). China Social Enterprise Report, FYSE. Acedido em setembro 10, 2017, em http://www.bsr.org/reports/FYSE_China_Social_Enterprise_Report_2012.PDF

Bechara, F.; Bernardino. S. (2018). A motivação para o trabalho dos voluntários - O Caso da Associação VENCER no Hospital Dr. Hélio Angotti em Uberaba. Livro de atas do IV Congresso ACINNET, Porto, 14-18 Maio, 122-123.

Bernardino, S.; Freitas Santos (2015). Papel das motivações do empreendedor na decisão de lançamento da iniciativa social, Portuguese Journal of Finance, Management and Accounting, 1 (2), 32-55.

Bloom, P.; Chatterji, A. (2009). Scaling social entrepreneurial impact. California Management Review, 51 (3), $114-$ 133.

Bloom, P.; Smith, B. (2010). Identifying the drivers of social entrepreneurial impact: Theoretical development and an exploratory empirical test of SCALERS. Journal of Social Entrepreneurship, 1 (1), 126-145.

Brunt, C. (2016). Human Resource Management in International NGOs- Exploring Strategy, Practice and Policy. London, Palgrave Macmillan UK.

CASE (2008). Developing the field of social entrepreneurship. [em linha]. Center for the Advancement of Social Entrepreneurship. Acedido em setembro 15, 2017, em http://www.caseatduke.org/documents/CASE_FieldBuilding_Report_June08.pdf

CASES - Cooperativa António Sérgio para a Economia Social (2016). Conta Satélite da Economia Social - 2013, acedido em setembro 14, 2017, em http://www.cases.pt/wp-content/uploads/2016/12/ Destaque_Conta_Satelite_da_Economia_Social.pdf.

Certo, S.; Miller, T. (2008). Social entrepreneurship: Key issues and concepts. Business Horizons, 51(4), 267-271.

Collis, D.;.Montgomery, C. (1981). Corporate strategy: A resource-based approach. Auckland: McGraw-Hill.

Dees, J. (1998). Enterprising nonprofits: What do you do when traditional sources of funding fall short? Harvard Business Review, 76 (1), 55-67.

Domenico, M.; Haugh, H.; Tracey, P. (2010). Social bricolage: theorizing social value creation in social enterprises. Entrepreneurship: Theory and Practice, 34 (4), 681-703.

Estrin, S.; Mickiewicz, T.; Stephan, U. (2013). Entrepreneurship, social capital, and institutions: Social and commercial entrepreneurship across nations. Entrepreneurship Theory and Practice, 37 (3), 479-504.

Ferreira, S. (2005). O que tem de especial o empreendedor social? O perfil de emprego do empresário social em Portugal. Publicações Oficina do CES, 223. Acedido em setembro 16, 2017, em http://www.ces.uc.pt/ publicacoes/oficina/223/223.pdf 
Gallagher, D.; Gilmore, A.; Stolz, A. (2012): The strategic marketing of small sports clubs: From fundraising to social entrepreneurship, Journal of Strategic Marketing, 20 (3), 231-247.

Guclu, A., Dees, J., Anderson, B. (2002). The process of social entrepreneurship: Creating opportunities worthy of serious pursuit. CASE Working Paper Series 3. Duke Fuqua School Duke University: Center for the Advancement of Social Entrepreneurship.

Harris, D.; Kor, Y. (2013). The role of human capital in scaling social entrepreneurship. Journal of Management for Global Sustainability, 1 (2), 163-172.

Hill, M.; Hill, A. (2000). Investigação por questionário. Lisboa: Edições Sílabo.

Hoogendoorn, B.; Hartog, C. (2011). Prevalence and determinants of social entrepreneurship at the macro-level. Scales Research Reports H201022, EIM Business and Policy Research. Acedido em junho 29, 2017, em http:// www.entrepreneurship-sme.eu/pdf-ez/H201022.pdf

INE- Instituto Nacional de Estatística (2016). Boletim mensal de estatística, 12. Acedido em setembro 15, 2017, em https://www.ine.pt/xportal/xmain? xpid=INE\&xpgid=ine_publicacoes\&PUBLICACOESpub_boui=133935\&PUBLICACOESmodo=2

Johnson, S. 2000. Literature review on social entrepreneurship. Canadian Centre for Social Entrepreneurship.

Korosec, R.; Berman, E. (2006). Municipal support for social entrepreneurship. Public Administration Review, 66 (3), 448-462.

Leadbeater, C. (1997). The rise of the social entrepreneur. London: Demos.

Leahy, G.; Villeneuve-Smith, F. (2009). State of social enterprise survey. London: Social Enterprise Coalition.

Lei n. ${ }^{\circ}$ 7/2009, de 12 de fevereiro. Diário da República, n. ${ }^{\circ}$ 30/20091998 - I Série A. Assembleia da República. Lisboa.

Lei n. ${ }^{\circ} 71 / 98$ de 3 de novembro. Diário da República n. ${ }^{\circ}$ 254/1998 - I Série A. Assembleia da República. Lisboa.

Lei n. ${ }^{\circ}$ 66/98 de 14 de outubro. Diário da República n. 237/1998 - I Série A. Assembleia da República. Lisboa.

Light, P. (2008). The search for social entrepreneurship. Washington, DC: Brookings Institution Press.

London, M.; Morfopoulos, R. (2010). Social entrepreneurship: How to start successful corporate social responsibility and community-based initiatives for advocacy and change. London: Routledge.

Lyons, T.; Lichtenstein, G. (2010). A community- wide framework for encouraging social entrepreneurship using the pipeline of entrepreneurs and enterprises model. In A. Fayolle, H. Matlay (eds.), Handbook of research on social entrepreneurship (252-270), Massachusetts: Edward Elgard.

Mair, J. (2010). Social entrepreneurship: taking stock and looking ahead. In A. Fayolle, H. Matlay (eds.), Handbook of research on social entrepreneurship (15-28), Massachusetts: Edward Elgard.

National Survey of Third Sector Organisations (2008). National Survey of Third Sector Organisations. Cabinet Office of the Third Sector. Acedido em março 10, 2017, em http://www.communityplanningtoolkit.org/sites/default/ files/OutcomesR4.pdf.

Nenobais, H., Kasim, A.; Maksum, I. (2016). he Capacity Development of Non-Profit Organizations in the Growth Stage (An Action Research Based on the SSM). Jurnal Kebijakan dan Administrasi Publik, 20, 2, 36-47.

Nogueira, R. (2014). Gestão de Recursos Humanos no Terceiro Setor: O Caso das Instituições Particulares de Solidariedade Social. Dissertação de Mestrado em Gestão de Recursos Humanos e Comportamento Organizacional, Instituto Superior Miguel Torga, Portugal.

Okpara, J.; Halkias, D. (2011). Social entrepreneurship: An overview of its theoretical evolution and proposed research model. International Journal of Social Entrepreneurship and Innovation, 1 (4), 4-20.

Parente, C. (2010). Gestão de Pessoas nas OSFL. In C. Azevedo, R. Franco, J. Meneses (Eds.), Gestão de organizações sem fins lucrativos (307-353), Lisboa: Vida Económica.

Parente, C. (ed.) (2014). Empreendedorismo Social em Portugal. Porto: Faculdade de Letras da Universidade do Porto/A3S.

Parente, C. (2013). A gestão de pessoas em organizações do terceiro setor. Work in Progress in Empreendedorismo social em Portugal: As políticas, organizações e as práticas de educação/formação. Acedido em maio 2, 2017, em http://web3.letras.up.pt/empsoc/index.php/produtos/category/11-artigos 
Parente, C., Costa, D., Santos, M.; Amador, C. (2013). Empreendedorismo social: Dos conceitos às escolas de fundamentação. As configurações de um conceito em construção. Work in Progress in Empreendedorismo social em Portugal: As políticas, organizações e as práticas de educação/formação. Acedido em abril 3, 2017, em http:// web3.letras.up.pt/empsoc/index.php/produtos/category/11-artigos

Parente, C., Santos, M., Marcos, V., Costa, D., Veloso, L. (2012). Perspectives of social entrepreneurship in Portugal: Comparison and contrast with international theoretical approaches. International Review of Social Research, $2(2), 113-134$.

Parsehyan, B. G. (2017). Human Resources Management in Nonprofit Organizations: A Case Study of Istanbul Foundation for Culture and Arts, In L. Mura (Ed.), Issues of Human Resource Management, InTech DOI: 10.5772/intechopen.68816. Acedido em setembro 15, 2017, em https://www.intechopen.com/books/issues-of-human-resource-management/human-resourcesmanagement-in-nonprofit-organizations-a-case-study-of-istanbul-foundation-for-cultur

Patel, S., Mehta, K. (2011). Life's principles as a framework for designing successful social enterprises. Journal of Social Entrepreneurship, 2 (1), 218-230.

Peredo, A., McLean, M. (2006). Social entrepreneurship: A critical review of the concept. Journal of World Business, $41(1), 56-65$.

Royce, M. (2007). Using human resource management tools to support social enterprise. Social Enterprise Journal, $3(1), 10-19$.

Schepers, C., Gieter, S., Pepermans, R., Bois, C., Caers, R., Jegers, M. (2005). How are employees of the nonprofit sector motivated? A research need. Nonprofit Management and Leadership, 16 (2), 191-208.

Selden, S. Sowa, J. (2016). Voluntary Turnover in Nonprofit Human Service Organizations: The Impact of High Performance Work Practices. Human Service Organizations Management, 39(3), 1-26.

Sharir, M., Lerner, M. (2006). Gauging the success of social ventures initiated by individual social entrepreneurs. Journal of World Business, 41 (1), 6-20.

Sousa, M., Baptista, C. (2011). Como fazer investigação, dissertações, teses e relatórios : segundo Bolonha. (2. ${ }^{a}$ edição). Lisboa: Pactor.

Teare, R., Ingram, H. (1993). Strategic management: A resource-based approach for the hospitality and tourism industries. London: Cassell.

Villeneuve-Smith, F., Chung, C. (2013). State of Social Enterprise Survey. London: Social Enterprise Coalition.

Young, D., Faulk, L., Harvey, N. (2009). The boundaries of social Enterprise: When can a failing business succeed in nonprofit form? EMES European Research Network, EMES Conferences Selected Papers Series.

Yunus, M. (2011). A empresa social (A. Saldanha, Trad., Tradução do original em inglês Building social business- The new kind of capitalism that serves humanity's most pressing needs). Lisboa: Editorial Presença.

Zhang, D., Swanson, L. (2013). Social entrepreneurship in nonprofit organizations: An empirical investigation of the synergy between social and business objectives, Journal of Nonprofit Public Sector Marketing, 25 (1), 105-125.

\section{BY-NC-ND}

